\title{
ATIVIDADE DE CAMPO E O ENSINO DE GEOGRAFIA FÍSICA: UMA PROPOSTA DE ROTEIRO CIENTÍFICO PARA A CHAPADA DO ARARIPE, CEARÁ, NE DO BRASIL
}

\author{
Joyce Clara Vieira Ferreira ${ }^{1}$ \\ Bárbara Danielle Andrade de Castro Praxedes ${ }^{2}$ \\ Marcelo dos Santos Chaves ${ }^{3}$ \\ Zuleide Maria Carvalho Lima ${ }^{4}$
}

\section{Resumo}

Este artigo tem por objetivo apresentar uma proposta de roteiro de campo voltada para os conteúdos das disciplinas relativas à Geografia Física, no Geopark do Araripe, Estado do Ceará, NE do Brasil. Na metodologia foram definidas quatro etapas de pesquisa: etapa précampo, destinada ao planejamento da atividade, originando um roteiro preliminar; etapa interação, momento de conscientizar os alunos sobre a importância da aula de campo e definir a atuação dos mesmos durante o desenvolvimento das atividades; e etapa pós-campo, análise das informações obtidas durante a excussão e elaboração da proposta desse artigo. Portanto, o resultado deste trabalho consistiu na apresentação do roteiro científico, atentando para as informações referentes à logística das atividades, bem como, para o conteúdo apresentado pelos professores em campo, sempre aliados à teoria estudada em sala de aula.

Palavras-chaves: Ensino; Geografia; Roteiro; Chapada do Araripe.

\section{ACTIVITY FIELD AND PHYSICAL GEOGRAPHY TEACHING - A PROPOSAL SCIENTIFIC SCRIPT FOR ARARIPE PLATEAU, CEARÁ, NORTHEAST OF BRAZIL}

\begin{abstract}
This article aims to present a proposal for a field script focused on the content of the subjects related to Physical Geography, in the region of the Araripe, covering the Geopark Araripe in the state of Ceara, NE Brazil. In the methodology were defined four stages of research: prefield stage, for the planning of field activity, resulting in a preliminary schedule; interaction

\footnotetext{
${ }^{1}$ Bacharela, Mestra e Doutoranda em Geografia pela Universidade Federal do Rio Grande do Norte (UFRN). Email: joyceclara@hotmail.com

${ }^{2}$ Licenciada e bacharelanda em Geografia pela Universidade Federal do Rio Grande do Norte (UFRN). Email: barbarapraxedes@hotmail.com

${ }^{3}$ Doutor em Geodinâmica e Geofísica pela Universidade Federal do Rio Grande Norte (UFRN) e Pós-Doutor pela Universidade de Lisboa (UL). Professor Associado I do Departamento de Geografia (DGE) da UFRN. Email: mschaves2007@gmail.com

${ }^{4}$ Doutora em Geodinâmica e Geofísica pela Universidade Federal do Rio Grande do Norte (UFRN). Professora Associada II do Departamento de Geografia (DGE) e Professora Permanente do Programa de Pós-Graduação e Pesquisa em Geografia (PPGE) da UFRN. Email: zuleide@ufrnet.br
}

Sociedade e Território - Natal. Vol. 28, N. 1, p. 174-192. Jan./Jun. de 2016 
step, time to educate students about the importance of field class and definition of their performance thereof during activities; and post-field phase, analysis of the information obtained during the field work and preparation of the proposal of this article. Therefore, the result of this article was the presentation of scientific script in the form of a report, noting the information on the development of logistics activities as well as to the content displayed by teachers in the field, always combined with the theory studied in class.

Keywords: Teaching; Geography; Script; Araripe Plateau.

\section{ACTIVIDAD DE CAMPO Y ENSEÑANZA GEOGRAFÍA FÍSICA - UNA PROPUESTA DE ITINERARIO CIENTÍFICA PARA LA CHAPADA DEL ARARIPE, CEARÁ, BRASIL, EL NORESTE}

\section{Resumen}

Este artículo tiene como objetivo una propuesta de plan de trabajo de campo dedicado a las disciplinas de la Geografía Física en Geoparque Araripe, Estado de Ceará, noreste de Brasil. La metodología tiene cuatro etapas de la investigación: etapa de pre-campo, para la planificación de la actividad; interacción paso, el tiempo para educar a los estudiantes sobre la importancia de la clase de campo y definir el rendimiento de ellos durante el desarrollo de las actividades; y la fase posterior a la de campo, análisis de la información obtenida durante la ejecución de una logística y la preparación de la propuesta de este artículo. Por lo tanto, el resultado de este artículo fue la presentación de itinerario científica, teniendo en cuenta la información sobre las actividades de logística, así como para el contenido mostrado por los maestros en el campo, siempre aliada a la teoría estudiada en clase.

Palabras clave: Educación; Geografía; Itinerario Científica; Chapada del Araripe.

\section{NOTAS INTRODUTÓRIAS}

As atividades de campo permitem concatenar a teoria e a empiria no sentido de contribuir no processo de aprendizagem dos alunos, auxiliando na elucidação de conteúdos complexos, bem como, nas suas práticas de campo relacionadas à ciência geográfica. Desse modo, entendemos que este é um recurso que desperta cada vez mais interesse dos alunos pela aprendizagem, quando realizado fora de sala de aula.

Diferente da geografia tradicional, onde a atividade de campo era apenas a observação e descrição dos elementos da paisagem, como aponta Gomes (1996), a geografia crítica aborda um conjunto de situações, onde exige uma maior preparação e contextualização do trabalho de campo para que possa assim fazer com que o aluno visualize e compreenda aquilo que foi visto em sala de aula, despertando dessa forma o senso crítico. 
Lima e Assis (2005) afirmam que são muitas as opções para se realizar um trabalho de campo pautado numa perspectiva sócio-constrututiva, "pois o espaço geográfico de vivência ou de conhecimento dos alunos oferece um leque de alternativas, tanto no meio urbano como no meio rural" (LIMA; ASSIS, 2005, p.111).

É nessa perspectiva que este artigo buscou apresentar uma proposta de roteiro científico de campo por quatro dias, voltada para aulas das disciplinas relativas à Geografia Física, na região da Chapada do Araripe, abrangendo o Geopark do Araripe e suas principais cidades: Crato, Juazeiro do Norte, Nova Olinda e Barbalha, localizadas no estado do Ceará (Figura 01).

Figura 01: Mapa de localização da Chapada do Araripe.

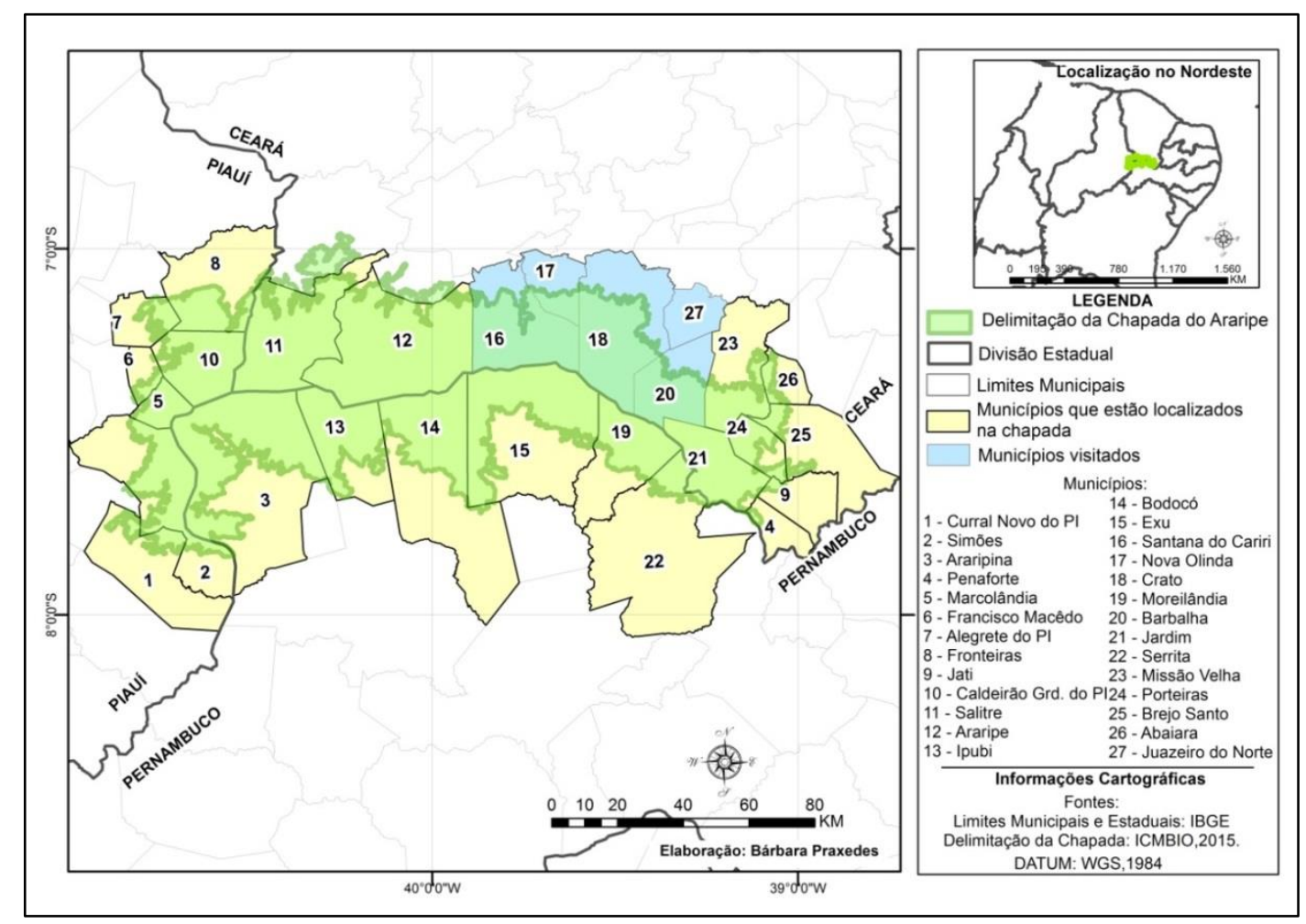

Fonte: Limites Municipais e Estaduais - IBGE. Delimitação da Chapada - ICMBIO, 2015. Elaboração: Bárbara Praxedes.

Portanto, a localidade da Chapada do Araripe foi selecionada por oferecer um ambiente com condições propícias no que diz respeito aos conteúdos apresentados em sala de aula e por concentrar cidades providas de infraestruturas capazes de receber grupos relativamente grandes, sendo este fato decorrente do turismo religioso fortemente instalado naquela região, o que acaba gerando esta característica peculiar. A região também conta com 
o GeoPark do Araripe que envolve a comunidade local, visitantes e seus aspectos naturais, sendo este último conhecido e de grande importância econômica para o lugar, devido a exploração do calcário laminado, além do apoio científico da Universidade Regional do Cariri (URCA).

\section{PROCEDIMENTOS METODOLÓGICOS}

A metodologia utilizada neste trabalho pautou-se nos trabalhos de Sansolo (1997) e Rodrigues e Otaviano (2001), consistindo na definição de quatro etapas, sendo as duas primeiras (Etapa pré-campo e Etapa interação) voltadas para o momento de preparação da excursão; a terceira etapa (Etapa campo) referente à realização da atividade de campo; e a quarta etapa (Etapa pós-campo) destinada aos resultados e avaliações pertinentes a atividades desenvolvidas.

A Etapa pré-campo destinou-se ao planejamento da atividade, resultando em um roteiro preliminar que posteriormente foi aprimorado. A Etapa interação consistiu no momento de conscientizar os alunos sobre a importância da atividade no que se refere à teoria repassada em sala de aula e a empiria vivenciada em campo buscando aprimorar o aprendizado dos conteúdos, além de definir a atuação dos mesmos durante a atividade (resultando em trabalhos de laboratório: desenvolvimento de práticas laboratoriais; e trabalhos de gabinete: os quais incluíram pesquisa e elaboração de um relatório).

Na Etapa campo foram desenvolvidos os trabalhos previamente planejados, tais como: visitações dos geossítios pertencentes à área Geopark do Araripe, coleta de materiais para posterior análise, registros fotográficos e anotações das observações de campo. Por fim, a Etapa pós-campo foi destinada a análise das informações obtidas durante a excursão e elaboração da proposta do artigo científico por parte dos autores.

Importante ressaltar que todas essas etapas de campo foram inicialmente planejadas em sala de aula, durante o semestre 2015.1, nas disciplinas de Geografia Física do Brasil e Pedologia, ambas do curso de Bacharelado de Geografia da Universidade Federal do Rio Grande do Norte, ministradas, respectivamente, pelos professores Dr. Marcelo dos Santos Chaves e Dra. Zuleide Maria Carvalho Lima. 


\title{
PANORAMA DOS ASPECTOS FÍSICOS DA CHAPADA DO ARARIPE
}

Considerada a maior bacia sedimentar do interior do Nordeste Brasileiro, Neumann (1999) afirma que a Bacia do Araripe é uma unidade geológica que compreende uma área de $12.000 \mathrm{~km}^{2}$. Estende-se por todo o Nordeste Brasileiro e adentra os Estados do Ceará, Piauí e Pernambuco. Conforme Martill (2007), esta bacia está subdividida nos grupos Araripe e Cariri, sendo composta pelas formações Cariri, Brejo Santo, Missão Velha, Abaiara, Rio das Batateiras, Crato, Ipubi, Santana e Exu.

A bacia do Araripe apresenta um grande potencial para exploração de recursos minerais, sendo os principais recursos explorados: o calcário laminado, os depósitos de gipsita e argila, e água mineral. A região apresenta uma das maiores jazidas fossilíferas do período Cretáceo do Brasil e do Mundo. Os calcários laminados do membro Crato, apresentam diversificados e abundantes registros de fauna e flora bem preservados.

\begin{abstract}
O ambiente que existia há cerca de 110 milhões de anos, e que permitiu a fossilização deste material, corresponde a um lago caracterizado por águas calmas, com alta taxa de precipitação de carbonatos e sais, e com pouco oxigênio. Tais características propiciaram a fossilização dos restos de animais e vegetais que se depositaram no fundo do lago juntamente com estes sedimentos que, mais tarde, originaram as lâminas de calcário, conhecidas localmente como "Pedra Cariri". (Governo do Estado do Ceará, p.44).
\end{abstract}

O registro geológico da região da Chapada do Araripe, faz referências às importantes fases evolutivas da história geológica da Terra e da região do Cariri. Os depósitos sedimentares desta bacia apresentam grandes diversidades de rochas, como os calcários, argilitos, arenitos e gipsitas, além dos grandes registros de fósseis, que nos dá uma ideia da vida existente naquela época, como peixes, pterossauros, tartarugas, folhas, troncos, etc.

A Chapada do Araripe é o compartimento de relevo de maior expressão regional. Conforme Santos et al. (2009), se trata de um relevo de natureza morfoestrutural, aclinal, formado a partir do preenchimento de uma bacia sedimentar do tipo rift (abortado). A Chapada do Araripe, apresenta um topo relativamente plano, o que permite a descrição da mesma como um relevo tabular, sem a existência de um front.

Segundo o site oficial do Geopark ${ }^{5}$, a Chapada do Araripe apresenta uma superfície de aproximadamente $180 \mathrm{~km}$ de comprimento na direção Leste-Oeste e uma largura que varia entre $30 \mathrm{~km}$ e $50 \mathrm{~km}$, que compreende os Estados do Ceará, Pernambuco e Piaú, com a

\footnotetext{
${ }^{5}$ www.geoparkararipe.org.br
}

Sociedade e Território - Natal. Vol. 28, N. 1, p. 174-192. Jan./Jun. de 2016 
altitude média variando entre 850 e 1000 m. A amplitude térmica na região é considerada baixa, com temperaturas variando de $23^{\circ}$ e $27^{\circ} \mathrm{C}$, chegando a $21^{\circ} \mathrm{C}$ no período entre maio e agosto. O clima é considerado tropical úmido, com regime de chuvas irregular, onde se concentra em poucos meses a chuva, variando anualmente de $700 \mathrm{~mm}$ a $1000 \mathrm{~mm} / \mathrm{ano}$.

De acordo com a FUNCEME (2009), na parte Sul da Chapada do Araripe, há o predomínio de solos mais profundos com domínio de latossolos derivados do arenito da Formação Exu. No sopé da chapada, onde ficam os municípios do Crato, Juazeiro e Barbalha, predominam solos profundos, avermelhados, com média fertilidade natural e boas condições para o uso agrícola, ocorrendo também os Argissolos Vermelhos. Já na Depressão Sertaneja, onde predominam rochas cristalinas ácidas, devido às condições climáticas, ocorrem solos rasos a pouco profundos.

No que se refere à cobertura vegetal da Chapada do Araripe, Silva Neto (2013) destaca: mata úmida (que contorna as bordas mais chuvosas), o cerradão e uma área de transição de cerradão/carrasco, que dão lugar ao carrasco nas áreas mais deprimidas e na posição central do planalto e as áreas de transição entre carrasco e cerradão e caatinga arbórea.

\section{GEOPARK ARARIPE - LUGAR DE RELEVÂNCIA HISTÓRICA, CULTURAL, GEOLÓGICA E PALEONTOLÓGICA}

O Geopark Araripe constitui um território de limites definidos, que possui geossítios com grande valor científico, histórico, cultural e ambiental. Tais sítios apresentam raridade, riqueza geológica e paleontológica, permitindo ampla compreensão sobre a história e evolução do planeta Terra e da biosfera (GOVERNO DO ESTADO DO CEARÁ, 2012).

Na tentativa de conservar o patrimônio natural, em 2005, foi enviada a UNESCO, com auxílio da Universidade Regional do Cariri (URCA), uma proposta de inserir o Geopark Araripe na rede global de Geoparques. Em 2006 foi finalmente aprovado, e em decorrência disso, um conjunto de ações de promoções das riquezas naturais do território em termos de educação ambiental, geoconservação e geoturismo, vem sendo realizadas.

Conforme o GOVERNO DO ESTADO CEARÁ (2012), entre os objetivos do Geopark Arapipe, destacamos a proteção e conservação dos sítios de maior relevância científico-cultural, denominados geossítios; proporcionar à população local e aos visitantes oportunidades de conhecer e compreender os contextos científicos, culturais e ecossistemas da 
região; intensificar relações com atividades turísticas e econômicas, com ênfase na arqueologia, paleontologia e na história evolutiva da Terra e da vida; divulgar a história do território, a cultura regional e suas manifestações, e as formas de utilização sustentável dos recursos naturais da região; promover a inclusão social, considerando a participação da sociedade como um dos pilares do desenvolvimento do Geopark Araripe enquanto território de ciência, educação e cultura; incentivar um turismo de qualidade, baseado nas múltiplas valências do território, através de uma estratégia de promoção e divulgação de nível internacional; e cooperar em articulação estreita com os parceiros do território e os poderes públicos municipal, estadual e federal, de forma a garantir um contínuo desenvolvimento do território.

\section{ROTEIRO DE ATIVIDADE DE CAMPO NA CHAPADA DO ARARIPE}

No intuito de aplicar os conhecimentos adquiridos em sala de aula através de uma atividade de campo, o grupo composto por alunos, professores e motorista (totalizando 30 pessoas), partiu da garagem da Universidade Federal do Rio Grande do Norte (UFRN) às 07h15min da manhã do dia 25 de abril de 2015 (sábado), com destino a cidade do Crato, localizada no Estado do Ceará, NE do Brasil, onde voltamos no dia 28 de abril de 2015 (terçafeira). As localidades visitadas e as respectivas atividades desenvolvidas na Chapada do Araripe serão apresentadas a seguir (Figura 02). 
Figura 02: Mapa das localidades visitadas na Chapada do Araripe-CE, Brasil.

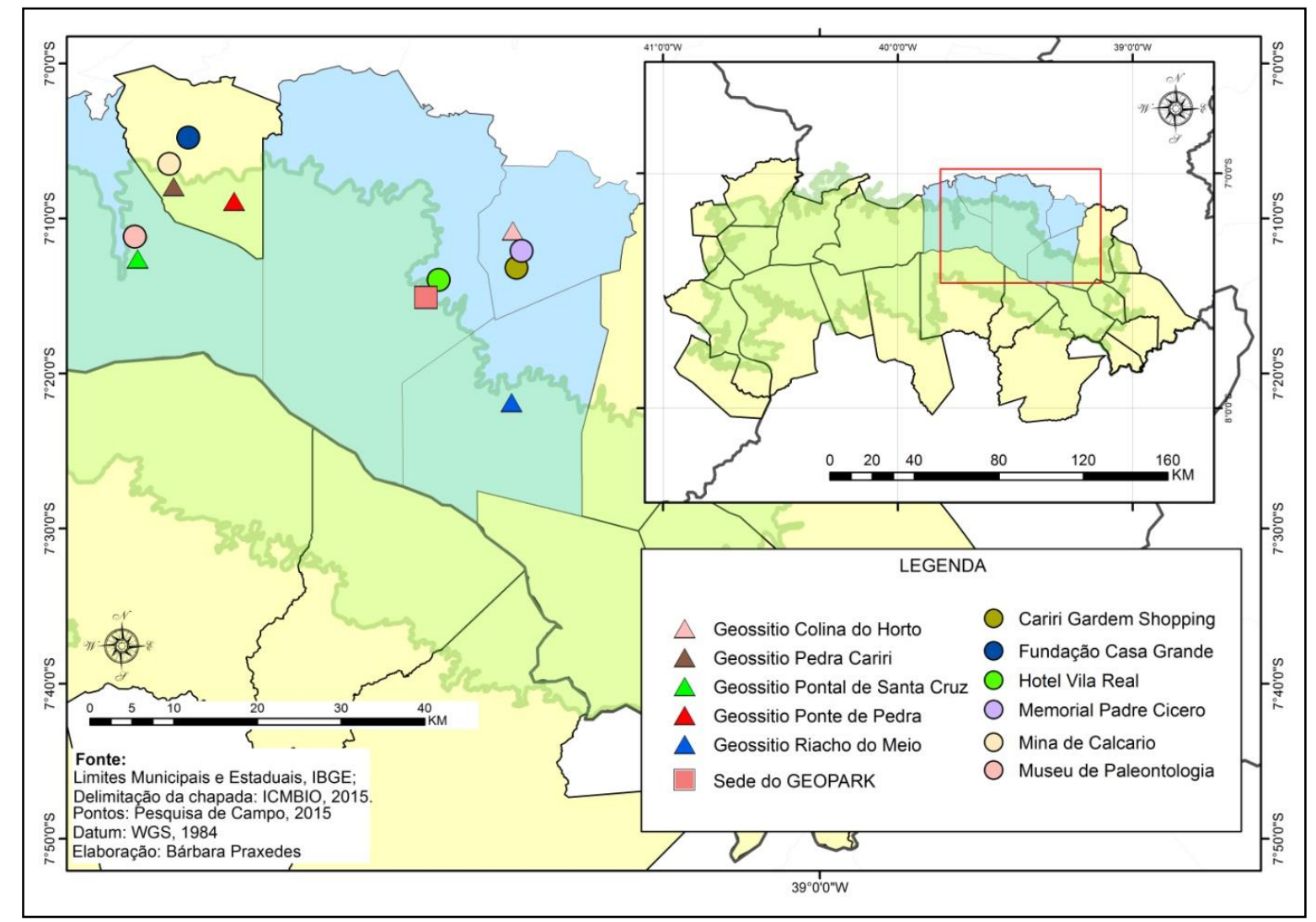

Fonte: Limites Municipais e Estaduais - IBGE. Delimitação da chapada - ICMBIO, 2015. Elaboração: Bárbara Praxedes.

\section{PRIMEIRO DIA DE ATIVIDADE DE CAMPO - CHAPADA DO ARARIPE}

Durante o trajeto de ida, no dia 25 de Abril de 2015 (sábado), percorrido pela BR 226, realizamos duas paradas no Estado do Rio Grande do Norte. A primeira às 08h20min, que destinou-se ao café da manhã no restaurante Veneza, na cidade de Tangará/RN. A segunda parada foi efetivada no município de Caicó/RN, na tão conhecida região do Seridó, para o almoço na Churrascaria Galileu.

Após o almoço, seguimos rumo ao município do Crato/CE, onde todos pernoitamos no Hotel Villa Real. O hotel está localizado no centro da cidade, onde se percebemos uma diversidade de estabelecimentos comerciais voltados para o ramo alimentício, além do comércio informal e uma feira popular, onde todos foram jantar e fazer compras de artesanato local da região. 


\section{SEGUNDO DIA DE ATIVIDADE DE CAMPO - CHAPADA DO ARARIPE}

No segundo dia de atividade de campo no Cariri (26 de abril de 2015, um domingo), fomos recebidos pela aluna Maíra, bolsista de iniciação científica, indicada pela Prof. ${ }^{a}$ Dr. $^{\text {a }}$ Simone Cardoso Ribeiro, da Universidade Regional do Cariri (URCA), para esclarecer atuar como guia neste dia de atividades. A saída do hotel ocorreu pontualmente às 08 h00min com destino ao geossítio denominado de Ponte de Pedra (Figura 03 A), localizada no Sítio Olho D’água de Santa Bárbara, próximo à rodovia CE-292, que liga o município do Crato ao de Nova Olinda.

Nesta localidade os professores Dr. Marcelo Chaves e Dr. ${ }^{\text {a }}$ Zuleide Lima apresentaram os afloramentos de arenitos envoltos por cimento carbonático (comprovado pelo uso do ácido clorídrico diluído a 10\%), bem como, suas estratificações que compõem a Formação Exu, com idade datada de 103 milhões de anos (Cretáceo Superior), sendo considerada a mais recente a ser depositada na Bacia do Araripe (Figura 03 B).

Figura 03: Geossítio Ponte de Pedra (A) e Arenito pertencente à Formação Exu (B).

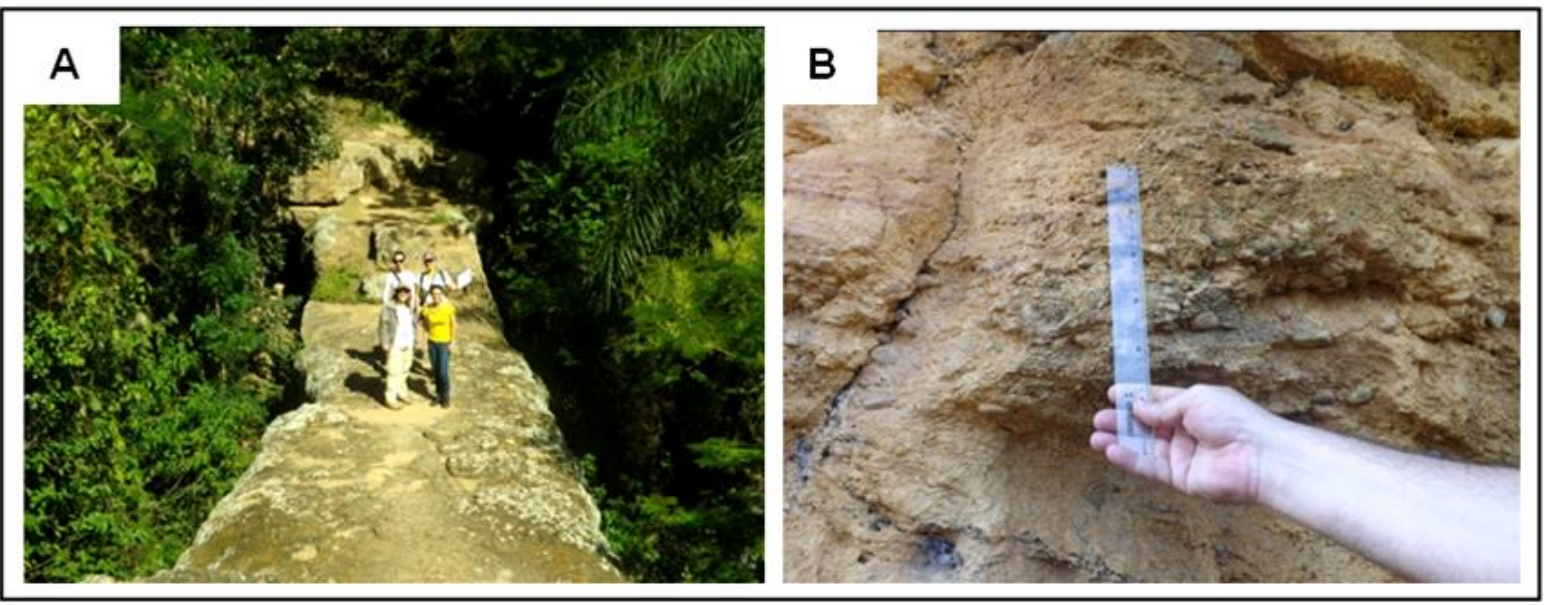

Fonte: Bárbara Praxedes, 26/04/2015.

A partir desse ponto, seguimos rumo ao centro do município de Nova Olinda, para visitação da Fundação Casa Grande (Memorial do Homem Kariri), uma organização não governamental, cultural e filantrópica criada em 1992 (Figura 04 A). O objetivo desta fundação está pautado na formação educacional de crianças e jovens por meio de seus programas: Memória, Comunicação, Artes e Turismo. Nesta ocasião, a nossa turma foi dividida em dois grupos, sendo conduzidos por guias mirins que apresentaram a história da casa, o acervo mitológico e arqueológico da pré-história do homem da região, o teatro Violeta 
Arraes, o cineclube, biblioteca e gibioteca. Além disso, foram apresentadas a rádio Voz da Liberdade e a Cooperativa Mista dos Pais e Amigos da Casa Grande (COOPAGRAN) que está voltada para o turismo, comercialização do artesanato local e formação dos guias mirins.

Em seguida, fomos visitar uma mineração de calcário laminado a céu aberto (Figura 04 B), onde foi possível observar a exploração deste tipo de rocha, também designada regionalmente de "Pedra Cariri". A extração ocorre no Membro Crato, pertencente à Formação Santana, onde é possível encontrar resquícios de vidas passadas, por meio dos fósseis incrustados nas rochas carbonáticas. Segundo Viana e Neumann (2002):

\begin{abstract}
A deposição desta unidade ocorreu durante o Cretáceo Inferior (cerca de 120 milhões de anos) e os fósseis contidos são relativamente abundantes e diversificados, incluindo invertebrados (ostracodes, conchostráceos, insetos, aracnídeos, biválvios e gastrópodes), vertebrados (actinopterígios, celacantos, pterossauros, quelônios, crocodilianos, lagartos, aves e anuros) e vegetais (algas, gimnospermas e angiospermas), além de icnofósseis (coprólitos, pistas de invertebrados e estramatólitos) e palinomorfos. (VIANA; NEUMANN, 2002, p. 114).
\end{abstract}

Os autores atentam também para exploração em demasia do calcário, uma vez que, ocasiona a destruição do patrimônio fossilífero, além de degradar a paisagem local, através do assoreamento de corpos hídricos e do aumento do potencial de erosão em áreas da Chapada do Araripe. Em meio à área de mineração foi possível observar a presença do mineral gibsita e incrustações de manganês com um aspecto dendrítico (Figura $04 \mathrm{C}$ ), além de estruturas de gretas de contração formadas em virtude do teor de argilas disperso na superfície do terreno.

\title{
Figura 04: Fundação Casa Grande - Memorial do Homem Kariri, localizada em Nova Olinda-CE (A); Mineração de calcário - Formação Crato (B); Amostra de calcário contendo óxido de manganês $(\mathrm{C})$.
}

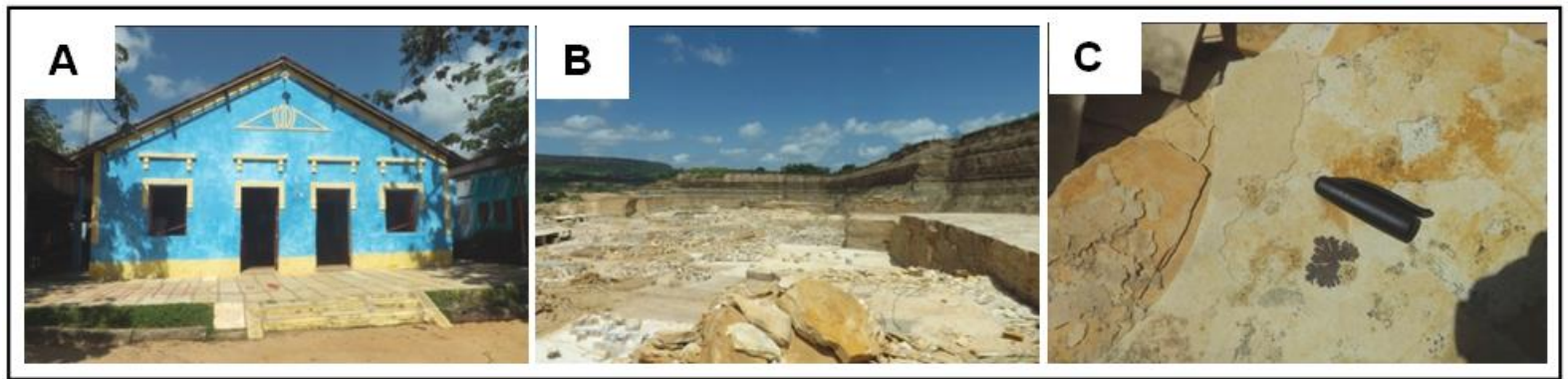

Fonte: Bárbara Praxedes, 26/04/2015. 
Após esta visita, seguimos para o Museu de Paleontologia da Universidade Regional do Cariri (URCA), em Santana do Cariri, museu esse fundado no ano de 1985 (Figura 05A). Este conta com um acervo bibliográfico voltado para as ciências da Terra, centro de intercâmbio científico, videoteca, recursos audiovisuais e fósseis (troncos petrificados, impressões de samambaias, pinheiros e plantas com frutos; moluscos, artrópodes; peixes, anfíbios e répteis) encontrados nas Formações Missão Velha e Santana, mais precisamente nos membros Crato, Ipubi e Romualdo (Figura 05 B).

Figura 05: Salão principal do Museu de Paleontologia da Universidade Regional do Cariri (URCA) (A); Fóssil de peixe, acervo do Museu de Paleontologia da Universidade Regional do Cariri (URCA) (B).
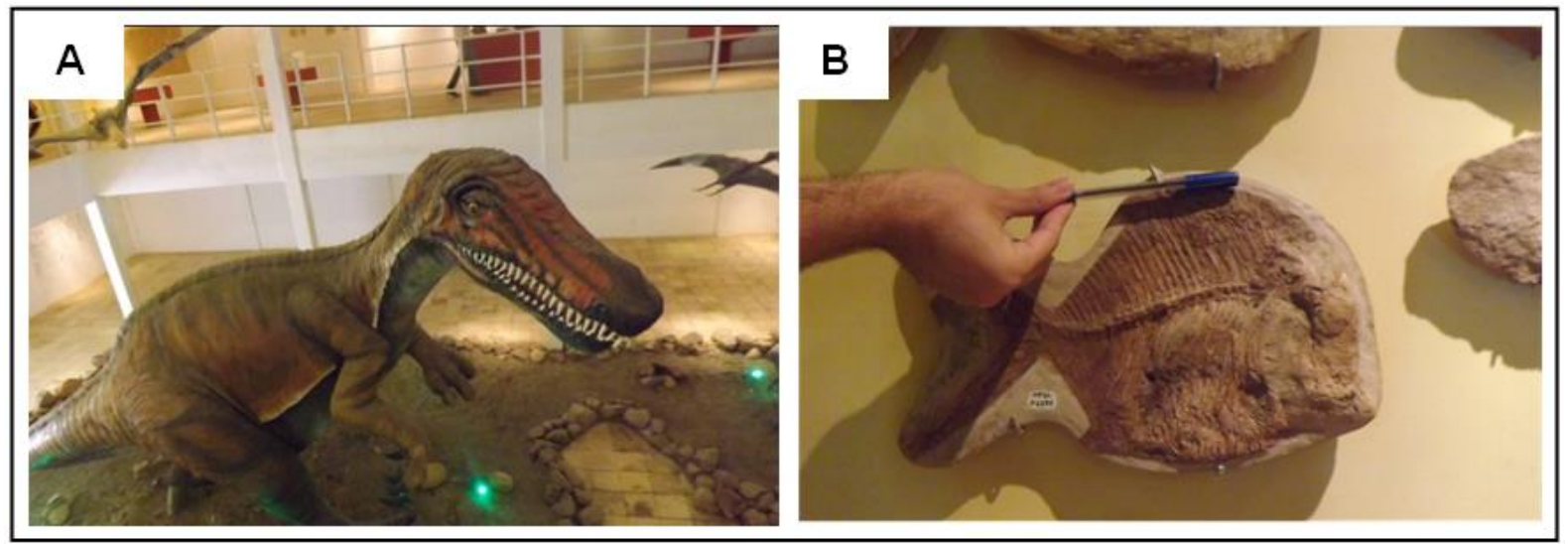

Fonte: Bárbara Praxedes, 26/04/2015.

Neste museu ainda existe um Núcleo de Difusão Tecnológica, que possui papel principal no tocante à difusão do conhecimento, através de cursos, treinamentos, encontros, palestras, além de representar um ponto de apoio para pesquisadores. Segundo GOVERNO DO ESTADO DO CEARÁ (2012), o museu mantém projetos de escavações permanentes de fósseis em toda área em que se insere a Bacia do Araripe (municípios de Nova Olinda e Santana do Cariri), constituindo uma ferramenta de fundamental importância contra a exploração mineral ilegal.

Finalizada a visita ao Museu de Paleontologia da Universidade Regional do Cariri (URCA), fomos almoçar no restaurante Ponta de Santa Cruz, onde chegarmos as 14:15h, restaurante esse localizado no Geossítio Ponta de Santa Cruz, a aproximadamente $750 \mathrm{~m}$ de altitude. Neste local (basicamente um mirante), observamos a paisagem da Chapada do Araripe com ênfase nos aspectos geomorfológicos, como o topo da chapada aplainada e cones 
de dejeção; sedimentológicos, principalmente os afloramentos dos arenitos da formação Exu; edáficos, como a mata úmida, cerradão, carrasco e caatinga arbórea conforme altimetria (SILVA NETO, 2013, p. 60) e seus processos físicos (erosão remontante, ações intempéricas, acumulação de materiais).

Para chegar a esse ponto, foi necessário locação de veículo com tração, pois a estrada (íngreme e mal conservada), possui difícil acesso para o ônibus e/ou carro de passeio. Porém, outra alternativa para se chegar ao Pontal de Santa Cruz, consiste parar em determinado trecho do percurso e seguir andando por meio de uma trilha que leva até o topo do mirante.

Ao finalizarmos o almoço, saímos do Pontal de Santa Cruz e seguimos com destino ao geossítio Pedra do Cariri (isso, em torno das 15:00h), onde percebemos a grande quantidade de rejeitos advindos das mineradoras de calcário desativadas. Adentrando em uma estrada carroçável, realizamos um perfil de solo com presença de muitas concreções de calcário. Nesta ocasião, realizamos algumas observações referentes aos atributos morfológico do solo (textura, cor, consistência, estrutura, transição entre horizontes, presença de nódulos e concreções carbonáticas, cerosidade, porosidade e permeabilidade), e coletamos amostras para posterior experimentos no Laboratório de Geografia Física (LabGeoFis) da Universidade Federal do Rio Grande do Norte.

\section{TERCEIRO DIA DE ATIVIDADE DE CAMPO - CHAPADA DO ARARIPE}

Neste terceiro dia de atividade de campo (27 de abril de 2015, uma segunda-feira), deixamos o hotel às $08: 30 \mathrm{~h}$ com destino ao geossítio Colina do Horto (Figura $06 \mathrm{~A}$ ), localizado a $3 \mathrm{~km}$ da cidade de Juazeiro do Norte. Neste momento, fomos guiados pela Prof. ${ }^{\text {a }}$ Dr. ' Simone Ribeiro, onde a mesma fez uma comunicação acerca dos aspectos geológicos, geomorfológicos, hidrográficos, pedológicos, edáficos, históricos, econômicos, culturais e os conflitos agrários da Chapada do Araripe, sendo fundamental para o entendimento dos aspectos gerais da região.

A referida professora relatou a história da bacia sedimentar do Araripe, delimitada pelo lineamento Patos (Serra de Caririaçu) e o lineamento Pernambuco, com sua formação iniciada através de um rifte abortado há aproximadamente 150 milhões de anos atrás, onde surgiu uma depressão que foi preenchida pela deposição dos estratos sedimentares em diferentes momentos conforme as condições ambientais vigentes de cada época. A colina do 
Horto representa uma porção do embasamento cristalino de origem metamórfica que outrora estava soterrado pelos sedimentos da bacia do Araripe. Com a intensificação dos processos erosivos, após o soerguimento desta região (65 milhões de anos), esse incelberg foi exumado, aflorando a rocha cristalina denominada de micaxisto.

O arenito poroso da Formação Exu, que recobre o topo plano da chapada do Araripe, atua como um filtro absorvedor das águas pluviais, concentrando a maior parte delas. Quando toca a superfície do terreno, as águas da chuva lavam os latossolos, carregando consigo os cátions trocados, por isso a vegetação torna-se menos densa no topo da chapada. Quando começa a ocorrer saturação, devido aos calcários pertencente aos membros Romualdo e Crato, a água surge nas nascentes, propiciando solos ricos em $\mathrm{CaCO}_{3}$, fazendo com as encostas fiquem mais úmidas, preservando o desenvolvimento da floresta perenifólia, que mantém sua umidade e realiza a retroalimentação com ajuda da serrapilheira.

Ainda segundo a Profa. Simone, os primeiros habitantes desta região foram os índios Cariris entre o século XVI e XVIII, em seguida ocorreu a colonização juntamente com a implantação da pecuária bovina próxima às margens dos rios. Mais tarde (século XIX), ocorre o desenvolvimento das atividades agrícolas, com destaque para cana-de-açúcar. Com o tempo, o processo de urbanização da região foi adensando, exigindo mais dos recursos hídricos, e por isso muitos rios deixaram de ser perenes e passaram a ser temporários. Atualmente, o processo de urbanização das cidades vivencia uma fase de verticalização, em meio ao desenvolvimento de uma economia voltada para o comércio e os serviços. Além disso, a região é detentora de duas universidades públicas (Federal e Estadual) e um pólo de medicina localizado no município de Barbalha.

A Profa. Simone, ainda atentou para os aspectos religiosos do Cariri, enfatizando a presença marcante do Padre Cícero e o coronelismo existente em todo Nordeste brasileiro. As questões agrárias também foram importantes na história desta região, abalizada pelos conflitos que permeiam a existência de grandes latifúndios e pequenas comunidades produtoras, a exemplo da extinta comunidade autossustentável do Caldeirão da Santa Cruz do Deserto.

Após esse panorama apresentado sobre a região do Cariri, fomos conhecer a famosa estátua do Padre Cícero e o Museu Vivo, ambos localizados no geossítio Colina do Horto. Seguimos então para o centro da cidade de Juazeiro do Norte, onde visitamos o Memorial do Padre Cícero, sendo este constituído por um museu com acervo voltado para diversos objetos 
de uso pessoal do referido padre, além de uma biblioteca e um auditório (Figura 06 B). Finalizamos a visita na Capela do Perpétuo Socorro, local onde foi sepultado o corpo do Padre Cícero, localizada no centro da cidade de Juazeiro do Norte.

Em seguida, já em torno das 12:30h, finalizamos os trabalhos de campo propriamente ditos, e fomos todos almoçar no Cariri Garden Shopping, lugar onde detém uma boa praça de alimentação. Após o almoço, seguimos com destino ao geossítio Riacho do Meio, a 7 km da cidade de Barbalha, onde realizamos uma trilha ecológica, sendo possível caracterizar um perfil de solo, verificando os seguintes aspectos: textura, cor, consistência, estrutura, transição entre horizontes, presença de nódulos e concreções, cerosidade, porosidade e permeabilidade, sendo definido como Latossolo (Figura $06 \mathrm{C}$ ).

Além disso, podemos conhecer três nascentes abastecedoras das comunidades residentes do entorno, sendo protegidas pelas às ações do GeoPark do Araripe. Finalizando, conhecemos a sede administrativa do GeoPark Araripe, (em torno das 16:30h), onde fomos recebidos por guias que distribuíram materiais explicativos e nos acompanharam por uma visita ao museu dos geossítios.

Figura 06: Geossítio Colina do Horto (A); Memorial do Padre Cícero (B); Perfil de solo, realizado na Pedra do Cariri $(\mathrm{C})$.

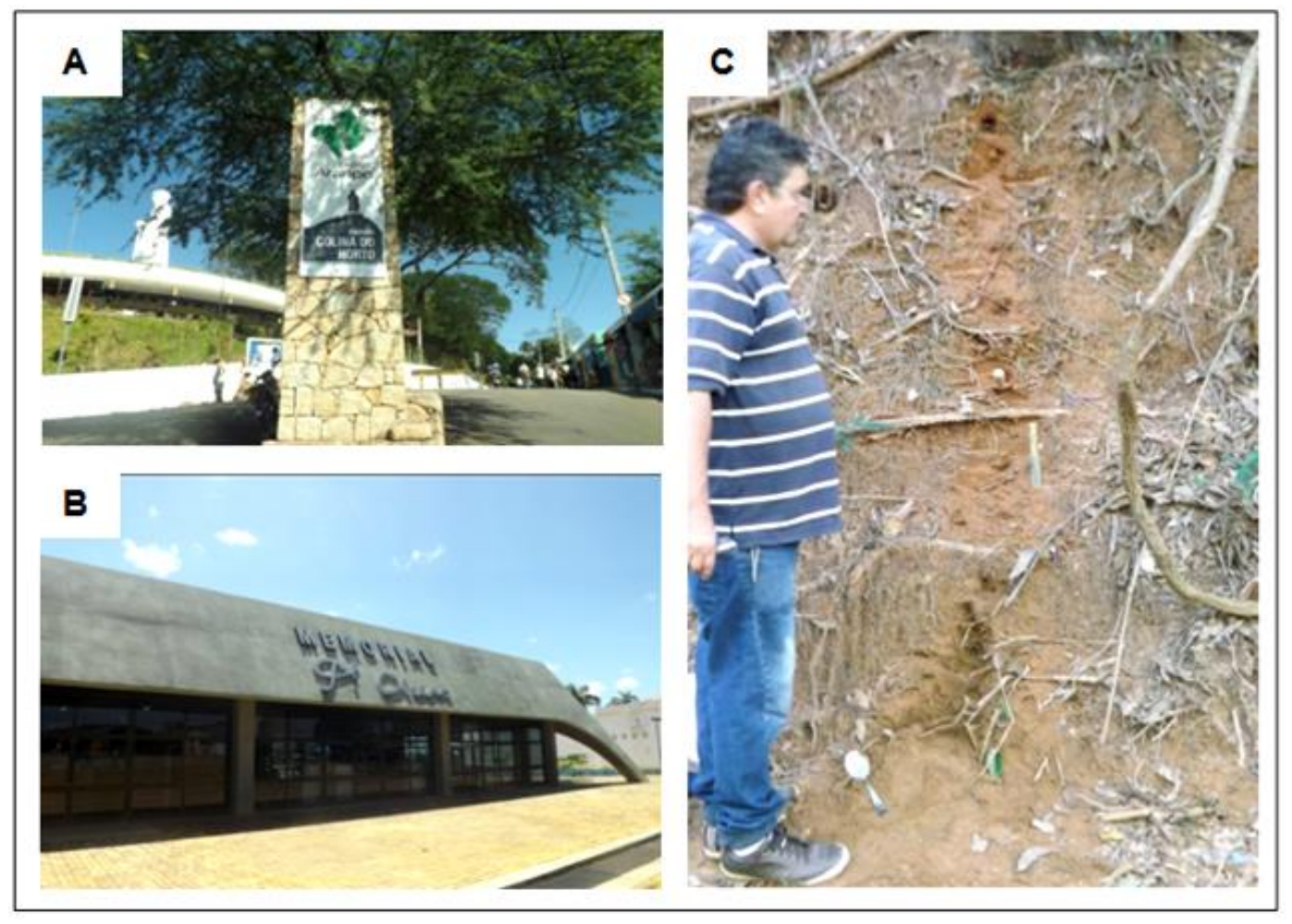

Fonte: Bárbara Praxedes, 27/04/2015.

Sociedade e Território - Natal. Vol. 28, N. 1, p. 174-192. Jan./Jun. de 2016 


\section{QUARTO DIA DE ATIVIDADE DE CAMPO - CHAPADA DO ARARIPE}

Neste quarto e último dia de atividades regressamos com o grupo para o município de Natal, deixando o hotel Villa Real às 8 h30min. Durante a viagem foi realizada uma parada no restaurante localizado em Caicó (Churrascaria Galileu) para refeição do almoço e em seguida o ônibus partiu rumo à garagem da UFRN, chegando a Natal por volta das $18 \mathrm{~h} 30 \mathrm{~min}$.

\section{SUGESTÕES PARA MANUTENÇÃO E ENRIQUECIMENTO DO ROTEIRO CIENTÍFICO DA CHAPADA DO ARARIPE}

Ao constituir uma expedição de campo com fins acadêmicos, exige-se dos organizadores um planejamento para alcançarmos êxito. Desse modo, mesmo planejado, temos que antever quaisquer percalços que possa a vir ocorrer. Pensando nisso, foram elencadas algumas observações acerca do roteiro proposto, que podem ser revisadas no sentido de manter e enriquecer as próximas excussões científicas destinadas a Chapada do Araripe.

Sendo assim, subdivididos em dois tópicos: Observações para os participantes da atividade de campo; e o outro, Observações para os organizadores da atividade de campo. Observações estas, referentes à manutenção e enriquecimento do roteiro científico na Chapada do Araripe.

- Observações para os participantes da atividade de campo - estas observações são destinadas para os alunos, professores e motorista do veículo condutor. Conforme a seguir:

1 - Atentar para vestimenta dos participantes. Estes devem usar calça comprida, tênis ou botas, chapéu, protetor solar, além disso, todos os alunos devem portar caderneta de campo, canetas e lápis, sacos para coletas de amostras e máquina fotográfica;

2 - Proibir o consumo de bebida alcoólica e fumo (lícitos e ilícitos) dentro do ônibus;

3 - Informar que todos são responsáveis por si e pelo bom desenvolvimento das atividades de campo;

4 - Exceto o deslocamento, os demais custos são de responsabilidade do participante da excursão. Diante disso, para se ter uma média das despesas investidas nesta atividade, foi elaborada uma tabela de custos, especificando os possíveis gastos (Tabela 01). 
Salienta-se que a tabela dos custos por pessoa para realização da aula de campo na Chapada do Araripe, foi elaborada com base na experiência de campo vivenciada pelos autores deste artigo no período de quatro dias (25 a 28 de abril de 2015.).

Tabela 01: custos por pessoa para realização da aula de campo na Chapada do Araripe. Os valores são dados em dólares ${ }^{6}$.

\begin{tabular}{|c|c|c|}
\hline REFEIÇÃO & DESCRIÇÃO & VALORES EM DÓLARES (\$) \\
\hline \multicolumn{3}{|c|}{$1 \%$ DIA DE ATIVIDADE DE CAMPO } \\
\hline CAFÉ DA MANHÃ (TANGARÁ - RESTAURANTE VENEZA) & PASTEL E CAFÉ & $\$ 1,59$ \\
\hline ALMOÇO (CAICÓ - CHURRASCARIA GALILEU) & BUFFET LIVRE - BEBIDA INCLUSA (COPO DE REFRIGERANTE) & $\$ 4,14$ \\
\hline JANTAR - CENTRO DO CRATO & VÁRIAS OPÇÕES & A PARTIR DE $\$ 3,18$ \\
\hline \multicolumn{3}{|c|}{$2^{\circ}$ DIA DE ATIVIDADE DE CAMPO } \\
\hline CAFÉ DA MANHÃ & FRUTAS, PÃES, TAPIOCA,FRIOS, OVOS, BOLOS, CAFÉ, LEITE. & INCLUSO NA HOSPEDAGEM \\
\hline ALMOÇO (PONTAL DE SANTA CRUZ) & BAIÃO DE DOIS (TRADICIONAL OU CREMOSO) E CHURRASCO & $\$ 4,14$ \\
\hline JANTAR - CENTRO DO CRATO & VÁRIAS OPÇÕES & A PARTIR DE $\$ 3,18$ \\
\hline \multicolumn{3}{|c|}{$3^{\circ}$ DIA DE ATIVIDADE DE CAMPO } \\
\hline CAFÉ DA MANHÃ & FRUTAS, PÃES, TAPIOCA,FRIOS, OVOS, BOLOS, CAFÉ, LEITE. & INCLUSO NA HOSPEDAGEM \\
\hline ALMOÇO (CARIRI GARDEN SHOPPING) & VÁRIAS OPÇÕES DE GRANDES FRANQUIAS & A PARTIR DE $\$ 4,78$ \\
\hline JANTAR - CENTRO DO CRATO & VÁRIAS OPÇÕES & A PARTIR DE $\$ 3,18$ \\
\hline \multicolumn{3}{|c|}{ 40 DIA DE ATIVIDADE DE CAMPO } \\
\hline CAFÉ DA MANHÃ & FRUTAS, PÃES, TAPIOCA,FRIOS, OVOS, BOLOS, CAFÉ, LEITE. & INCLUSO NA HOSPEDAGEM \\
\hline ALMOÇO (CAICÓ - CHURRASCARIA GALILEU) & BUFFET LIVRE - BEBIDA INCLUSA (COPO DE REFRIGERANTE) & $\$ 4,14$ \\
\hline \multicolumn{3}{|c|}{ OUTROS CUSTOS } \\
\hline HOTEL VILLA REAL & QUARTOS COM BANHEIRO PRIVATIVO E AR CONDICONADO & $\$ 42,99$ \\
\hline ENTRADA NO MUSEU DE PALEONTOLOGIA (URCA) & VISITA GUIADA AO ACERVO DO MUSEU & $\$ 1,59$ \\
\hline DESLOCAMENTO PARA O PONTAL DE SANTA CRUZ & REALIZADO POR MEIO DE VAN & $\$ 1,59$ \\
\hline VALORES ADICIONAIS & POR EXEMPLO: ÁGUA, SOUVENIRS, ARTESANATO & $\$ 15,92$ \\
\hline TOTAL DO INVESTIMENTO: & & $\$ 90,42$ \\
\hline
\end{tabular}

Fonte: Elaboração própria.

* Observações para os organizadores da atividade de campo - estas observações são destinadas para os professores responsáveis pela excursão para Chapada do Araripe.

1 - Realizar as visitas de campo no período de estiagem (julho a janeiro), evitando os meses de fevereiro, março, abril, maio e junho; devido o acesso das estradas que podem ser prejudicados em virtude das precipitações pluviométricas;

2 - Realizar visitação ao geossítio do Parque dos Pterossauros localizado no Sítio Canabrava (propriedade da Universidade Regional do Cariri - URCA), a 2,5km de Santana do Cariri, considerado um dos principais geossítios do Geopark Araripe, por ser a primeira localidade

\footnotetext{
${ }^{6}$ Dólar comercial cotado a R\$ 3,14 em 07 de julho de 2015.
}

Sociedade e Território - Natal. Vol. 28, N. 1, p. 174-192. Jan./Jun. de 2016 
onde foram encontrados os fósseis de animais. Nesta ocasião, o acesso a este local foi impossibilitado em virtude das chuvas ocorridas durante a semana anterior à chegada do grupo da UFRN;

3 - No retorno ao município de Natal, solicitar ao condutor do veículo da universidade a realização de uma parada no percurso entre o município do Crato-CE e Caicó-RN, visto que este trajeto é considerado longo e exaustivo (aproximadamente cinco horas de viagem);

4 - A saída do Hotel Villa Real, localizado no município do Crato, pode ser realizada mais tarde (após às $8 \mathrm{~h} 30 \mathrm{~min}$ ) para evitar o trânsito no horário de pico entre os municípios de Parnamirim e Natal, ambos localizados no Estado do Rio Grande do Norte.

Por fim, entendemos que estas informações são relevantes para o bom desenvolvimento das atividades de campo na Chapada do Araripe. Além disso, é importante destacar que essas ressalvas podem ser complementadas e/ou ajustadas conforme os objetivos da atividade de campo de cada semestre e de seus organizadores.

\section{CONSIDERAÇÕES FINAIS}

O ensino voltado para teoria e empiria da ciência geográfica possui grande relevância no que se refere à aprendizagem, pois possibilita ao aluno conhecer o ambiente e alguns fragmentos da realidade em que vive as populações, consistindo numa ferramenta importante na formação profissional do geógrafo crítico.

Nesse sentido, a aula de campo surge como uma alternativa metodológica para o ensino de geografia, despertando o interesse dos alunos devido seu caráter prático/científico. Por assumir clara relevância, o roteiro de campo elaborado para Chapada do Araripe foi proposto objetivando mantê-lo pelos próximos semestres, uma vez, que existe nesta localidade, infraestrutura logística e científica, capaz de receber os estudantes de graduação em geografia da UFRN. Ressalta-se que o roteiro elaborado está passível de adequações para realidade dos conteúdos das disciplinas concernentes a Geografia.

Portanto, o esforço concentrado na elaboração deste roteiro de campo, buscou auxiliar professores da graduação em geografia na organização de trabalhos de campo voltados para região da Chapada do Araripe, mais precisamente no Geopark Araripe - CE. Tal localidade oferece um ambiente com condições propícias no que diz respeito aos conteúdos de geografia 
física apresentados em sala de aula, e por concentrar cidades providas de infraestruturas capazes de recepcionar grupos relativamente grandes, além de contar com o apoio científico oferecido pela Universidade Regional do Cariri (URCA).

\section{REFERÊNCIAS}

FUNCEME, Fundação Cearense de Meteorologia e Recursos Hídricos. Caracterização das bacias hidrográficas do estado do Ceará. Fortaleza, 2009. no prelo.

GOMES, Paulo César da C. Geografia e modernidade. Rio de Janeiro: Bertrand Brasil, 1996.

Governo do Estado do Ceará. Geopark Araripe: Histórias da Terra, do Meio

Ambiente/Governo do Estado do Ceará/Secretaria das cidades/Projeto Cidades do Cerará Cariri Central - Crato-CE, 2012. 167p.

LIMA, Vanuzia Brito \& ASSIS, Lenilton Francisco. Mapeando alguns roteiros de trabalho de campo em Sobral-CE: Uma contribuição ao ensino de Geografia. Revista da Casa da Geografia de Sobral, Sobral, v.6/7, n. 1 p. 109 - 121, 2004/2005.

MARTILL, David. The age of the Cretaceous Santana Formation fossil Konservat Lagerstätte of north-east Brazil: a historical review and an appraisal of the biochronostratigraphic utility of its palaeobiota, Cretaceous Research, v. 28, p. 895-920, 2007.

NEUMANN, Virginio Henrique de Miranda Lopes. Sistemas lacustres aptiense-albanienses de la Cuenca de Araripe, NE, Brasil. Barcelona, 1999, 250f. Tese Doutorado, Universidad de Barcelona.

RODRIGUES, Antonia Brito; OTAVIANO, Claudia Arcanjo. Guia Metodológico de Trabalho de Campo em Geografia. Revista de Geografia, Londrina, v. 10, n. 1, p. 35-43, jan./jun. 2001.

SANSOLO, Davis Gruber. A importância do trabalho de campo no ensino de geografia e para a educação ambiental. Anais. ENCONTRO DE GEÓGRAFOS DA AMÉRICA LATINA, $6^{\circ}$. 1997. Buenos Aires: Anais. Buenos Aires, 1997. Disponível em Observatório Geográfico da América Latina:

http://www.observatoriogeograficoamericalatina.org.mx/egal6/Teoriaymetodo/Metodologicos 1549.pdf Acesso: 18 maio 2015 às 13h28min.

SANTOS, Cristiano Aprigio dos; FLORENZANO, Teresa Gallotti; NORA, Eloi Lennon Dalla. Estudo geológico-geomorfológico da sub-bacia leste do Araripe com aplicação de variáveis morfométricas derivadas a partir de dados da SRTM. SIMPÓSIO BRASILEIRO DE SENSORIAMENTO REMOTO, XIV., 2009, Natal, Brasil. Anais. Natal: INPE, 2009. p. $3355-3362$. 
SILVA NETO, Basílio. Perda da vegetação natural na Chapada do Araripe (1975/2007) no estado do Ceará. 2013. 185f. Tese. (Doutorado em Geografia) - UNESP, Departamento de Geografia, Rio Claro/SP, 2013.

VIANA, Maria Somália Sales \& NEUMANN, Virgínio Henrique Lopes. Membro Crato da Formação Santana, Chapada do Araripe, CE: riquíssimo registro de fauna e flora do Cretáceo. In.: SCHOBBENHAUS, Carlos et al. Sítios geológicos e paleontológicos do Brasil. v. 1. Brasília: DNPM, 2002. Disponível em: http://sigep.cprm.gov.br/sitios.htm\#Vol1 Acesso: $17 / 05 / 2015$ às $12 \mathrm{~h} 30 \mathrm{~min}$.

Recebido em Agosto de 2015

Aprovado em Abril de 2016

Publicado em Junho de 2016 